\title{
PRODUÇÃO E CARACTERIZAÇÃO DE BIOCARVÃO A PARTIR DE BIOSSÓLIDOS ARMAZENADOS EM BAG'S GEOTÊXTEIS NO MUNICÍPIO DE RANCHARIA - SP
}

\section{BIOCARBON PRODUCTION AND CHARACTERIZATION FROM STORED BIOSOLIDS IN GEOTEXTILE BAGS IN RANCHARIA - SP}

Beatriz Regina de Ângelo ${ }^{1}$, Rafaela Pelegrini Vital ${ }^{1}$, Marcelo Rodrigo Alves $^{1}$, Jaqueline Oliveira da Silva ${ }^{1}$, Melissa Arantes Pinto ${ }^{1}$, Daniel Ângelo Macena ${ }^{2}$, Janardelly Gomes de Souza ${ }^{1}$

${ }^{1}$ Universidade do Oeste Paulista - UNOESTE, Presidente Prudente, SP. ${ }^{2}$ Universidade Virtual do Estado de São Paulo-UNIVESP.

E-mail: marceloalves@unoeste.br

RESUMO - O lodo de esgoto refere-se a um subproduto rico em nutrientes e matéria orgânica proveniente das estações de tratamento e passou a ser um desafio para vários segmentos de pesquisa encontrar um destino racional e sustentável a esse material. Nesse contexto, a carbonização de biomassa (pelo processo de pirólise) resulta no biocarvão, caracterizado por um material bastante estável, com propriedades físicas e químicas específicas e pode representar uma ferramenta de grande importância para esse desafio. Assim, o objetivo do presente trabalho foi transformar, por processo de pirólise, pequenas porções do biossólido gerado na ETE de Rancharia em biocarvão. Além disso, tanto o biossólido quanto os biocarvões gerados foram submetidos a análises físicas, químicas e estruturais a fim de proceder a suas respectivas caracterizações. A partir das análises, constatou-se o tratamento submetido à temperatura de $550^{\circ} \mathrm{C}$ como a melhor opção para possíveis aplicações.

Palavras-chave: biossólido; pirólise; biocarvão.

ABSTRACT - Sewage sludge refers to a nutrient-rich by-product and organic matter from treatment plants and has become a challenge for many research segments to find a rational and sustainable destination for this material. In this context, the carbonization of biomass (by the pyrolysis process) results in biochar, characterized by a very stable material with specific physical and chemical properties and can represent a very important tool for this challenge. Thus, the objective of the present work was to transform, by pyrolysis process, small portions of the biosolid generated in Rancharia ETE into biochar. In addition, both the biosolid and the generated bicarbons were subjected to physical, chemical and structural analyzes in order to proceed with their respective characterization. From the analysis, it 
was found that the treatment submitted to temperature of $550^{\circ} \mathrm{C}$ as the best option for possible applications.

Keywords: biosolid; pyrolysis; biochar. 


\section{INTRODUÇÃO}

Em decorrência da revolução industrial sucedida em meados do século XVIII, deu-se início a um crescente aumento mundial na produção e dispersão de materiais, processo no qual impulsionou o consumismo desenfreado pela humanidade, em que geralmente caracterizava-se por consumo de produtos dispensáveis. Simultaneamente a produção, houve outra variável que ampliou de forma demasiada: $A$ densidade demográfica em que os moradores das áreas rurais migravam constantemente para as áreas urbanas na pretensão de empregabilidade e desenvolvimento. Sendo assim, com as cidades superlotadas, fez-se necessário o aprimoramento do sistema de saneamento básico para atender de forma equilibrada todos os moradores e promover a saúde dos indivíduos.

Pertinente ao que foi fundamentado, Fonseca e Prado Filho (2010) mencionam que em virtude da intensa atração da população do campo à cidade e dos diversos problemas suscitados desse processo nos centros urbanos europeus, o Estado procurou intervir na questão do saneamento nas cidades no intuito de livrar a população da proximidade dos esgotos, dos resíduos, além de outros problemas de âmbito sanitário.

Nessa óptica, criou-se no Brasil a Estação de Tratamento de Esgoto (ETE), em que a mesma é responsável pela coleta do efluente doméstico bruto e a transformação do mesmo em um líquido não nocivo, e que atenda as normas de padrão de lançamento do efluente em corpo d'água, ditado pela Resolução CONAMA 357/06. No processo de tratamento dos efluentes domésticos existem etapas sequenciais, sendo 0 gradeamento; desarenador; decantador primário; tanque de aeração; decantador secundário; cloração e disposição em corpo d'água. Porém nesse processo, origina-se um subproduto do esgoto cognominado por lodo de esgoto, em que o mesmo contém a parte grosseira do efluente que se dissipou durante o processamento do líquido, decantando durante as fases, do qual é retirado e depositado em bags, para não serem dispostos diretamente em aterros sanitários comprometendo sua vida útil, e também em razão do conhecimento insuficiente do efeito do subproduto em longo prazo, já que podem conter microrganismos patológicos e nocivos ao solo e ao lençol freático.

Desse modo, uma das principais adversidades presentes nesse processo, enfrentado por grande parte dos municípios brasileiros refere-se à disposição do lodo de esgoto ao meio ambiente, em que frequentemente são realizados diversos estudos a fim de obter novas alternativas para essa questão.

Conforme Mahadal et al. (2016), uma das alternativas mais bem discorridas acerca desse desafio é a disposição do lodo de esgoto tratado termicamente (biocarvão) em solos, e posteriormente, sua aplicação na agricultura, de modo a atender a legislação vigente. Essa alternativa torna-se comumente viável em decorrência da presença de alto teor de resíduos orgânicos e nutrientes necessários às plantas e solos. Porém, como mencionado, essa atividade requer um tratamento do lodo de esgoto previamente a sua aplicação ao corpo receptor para que haja a redução de possíveis elementos tóxicos e metais pesados presentes, além de ser necessário um manejo de profissional capacitado, incluindo um monitoramento e estudo para evitar efeitos indesejáveis consequentes da aplicação, sobretudo na saúde humana, segundo o site EcoDebate (2009).

A referida prática quando bem executada e manejada, fornece benefícios concernentes à disposição do lodo de esgoto, visto que se trata de uma solução ambiental adequada e por outro lado, pode propiciar vantagens no âmbito agrícola e econômico. Sendo assim, o estudo possuiu como objetivo principal produzir e caracterizar biocarvões proveniente do lodo de esgoto da ETE do município de Rancharia - SP. 


\section{JUSTIFICATIVA}

Durante alguns anos, o Serviço de Água e Esgoto do município de Rancharia SP utilizou-se do sistema de bag's geotêxteis para filtrar o esgoto gerado e armazenar os sólidos contidos no mesmo. Atualmente a área destinada para esse serviço encontra-se em estado de abandono e os bags cheios de uma mistura de materiais orgânicos e inorgânicos. No entanto, suscitou numa adversidade, pois as autoridades competentes não sabem como agir e qual o destino apropriado para esse material. Entretanto, isso não é uma particularidade deste munícipio, visto que encontrar um destino racional e sustentável para o lodo de esgoto proveniente das diversas estações de tratamento, passou a ser um desafio para vários segmentos de pesquisa.

Vale ressaltar que esses materiais são comprovadamente ricos em nutrientes e matéria orgânica e que, em contrapartida têm-se no Brasil, milhares de hectares de solos degradados com várias limitações químicas, tais como baixa fertilidade natural, acidez elevada e baixo teor de matéria orgânica. Mesmo as áreas "não degradadas" ou utilizadas para fins agrícolas, a manutenção da produção só ocorre devido ao aporte de fertilizantes e corretivos químicos, que na sua maioria são provenientes de fontes finitas.

Assim, destaca-se a importância de encontrar uma maneira segura e viável do uso do lodo como condicionador do solo, de maneira que isso possa representar ganhos econômicos, sociais e ambientais.

\section{OBJETIVOS}

\subsection{OBJETIVO GERAL}

O presente trabalho tem como objetivo produzir e caracterizar biocarvões proveniente do lodo de esgoto da ETE do município de Rancharia - SP a partir de análises físico-químicas.

\subsection{OBJETIVOS ESPECÍFICOS}

- Realizar análise termogravimétrica do lodo puro para a definição das melhores temperaturas de pirólise;

- Produzir os biocarvões em condições de laboratório em diferentes temperaturas;

- Caracterizar os biocarvões por meio das análises de balanço de massa, capacidade de troca catiônica, condutividade elétrica, potencial hidrogeniônico $(\mathrm{pH})$, análises imediatas, determinação do tamanho e densidade de partículas, obtidos em diferentes temperaturas;

- Realizar análises de Microscopia Eletrônica de Varredura (MEV) e Espectroscopia de Energia Dispersiva (EDS); e

- Identificar a melhor temperatura de pirólise estudada (Material com resultados mais satisfatórios).

\section{REVISÃO BIBLIOGRÁFICA}

\subsection{TRATAMENTO DE EFLUENTES}

O crescimento demográfico no Brasil sucedeu-se de modo vertiginoso, acarretando na formação de cidades com infraestrutura insuficiente para comportar tamanha população. Em virtude disso, os grandes centros e metrópoles urbanas passaram a enfrentar diversos desafios, sobretudo no âmbito ambiental. Nesse contexto, há alguns anos, a população possuía o hábito ambientalmente incorreto de lançar seus efluentes diretamente nos corpos hídricos, poluindo-os, procedendo em situações de alta negligência, como exemplo, a do rio Tietê na maior cidade do país - São Paulo. A partir desse problema, criou-se algumas políticas de incentivo ao saneamento básico e então, a instalação de Estações de Tratamento de Esgotos (ETE's), a fim de tratar adequadamente os efluentes previamente aos lançamentos aos corpos mananciais (PIRES, sd), podendo ser lagos, rios, oceanos e até mesmo, solos, para que assim os esgotos domésticos e industriais não fomentem em impactos ambientais e problemas de saúde pública (PEDROZA et al., 2003). 
Os tratamentos funcionam de formas distintas, amenizando o seu teor de matéria orgânica através da oxidação, além da formação de flocos que sucede no aumento da densidade, propiciando a sedimentação e consequentemente, a remoção dessa massa sólida resultante, designado por lodo de esgoto ou biossólido (PEDROZA et al., 2003). Segundo PIRES (sd), biossólido caracteriza-se na denominação de lodo de esgoto quando o mesmo já encontra-se tratado ou processado, apresentando propriedades que possibilitam sua reciclagem de modo racional e ambientalmente correto.

A partir da instalação das ETE's, uma nova adversidade ambiental foi gerada: $A$ destinação do subproduto do tratamento de efluentes, o lodo de esgoto.

\subsection{LODO DE ESGOTO}

Preliminarmente, caracteriza-se lodo de esgoto como um resíduo procedente do tratamento de efluentes, processo que ocorre habitualmente nas ETE's (PIRES, sd).

O lodo de esgoto possui inúmeros riscos à saúde pública e ao meio ambiente, além da possibilidade da presença de compostos fármacos e outros restos metabólicos humanos que não se desintegram em meio ao tratamento e que ainda, as características do lodo de esgoto são decorrentes do tipo de tratamento do qual o mesmo foi submetido, em que pode ser de natureza química, física e/ou biológica (AREIAS et al., 2017). Além disso, Bettiol e Camargo (2006) e Paredes Filho (2011) ressalvam que a composição do efluente e do lodo de esgoto diferencia-se também em função do local de origem, podendo ser de cunho industrial ou doméstico, bem como em função da época do ano, entre outros fatores.

Concernente à disposição do lodo de esgoto, tanto Pedroza et al. (2003), quanto Bittencourt, Aisse e Serrat (2017) revelam que a coleta e tratamento de esgotos tendem a expandir-se, bem como a melhoria dos processos dos mesmos, elevando proporcionalmente a produção de lodo em que de modo consequente, acarretará em maiores preocupações acerca da destinação final desse subproduto, visto que nos dias atuais, as empresas de saneamento já vêm enfrentando esse desafio.

Referente ao empecilho apontado pelas empresas há algumas opções consideravelmente viáveis, sob pontos de vista ambiental, econômico, técnico e operacional, no propósito de dispor o lodo de esgoto de maneira ambientalmente correta, podendo ser em uso agrícola, destinação em aterro sanitário ou industrial licenciado. (GODOY apud BITTENCOURT; AISSE; SERRAT, 2017). Embora haja demais alternativas para a sua disposição, como incineração (XU et al. apud BITTENCOURT; AISSE; SERRAT, 2017), biomassa para a geração de energia (KOGA et al. apud BITTENCOURT; AISSE; SERRAT, 2017), bem como sua utilização para a fabricação de cimento (YOKOHAMA apud BITTENCOURT; AISSE; SERRAT, 2017) e de materiais de construção, (OKUNO et al.; JORDAN et al.; MATSUMIYA apud BITTENCOURT; AISSE; SERRAT, 2017) essas ainda representam opções incipientes no Brasil, no entanto, muito aplicadas em outros países do mundo.

Segundo Areias et al. (2017), em alguns países do continente europeu e da América do Norte, usualmente incineram o lodo de esgoto e depois o depositam em aterros sanitários ou o utilizam na agricultura, distintivamente do Brasil que normalmente é descartado em aterros sanitários.

Por referir-se a um resíduo orgânico rico em matéria orgânica, podendo conter teores significativos de nitrogênio, fósforo, zinco, cobre, manganês e molibdênio, entre outros, o biossólido pode tornar-se um insumo de grande relevância para a agricultura e para o solo, visto que, em comparação às demais alternativas, essas possuem maior viabilidade econômica (RIGO et al., 2014). 


\section{METODOLOGIA}

Para melhor compreensão dos procedimentos metodológicos do presente trabalho, apresenta-se na Figura 1 um fluxograma com as principais atividades que foram desenvolvidas.

Figura 1. Fluxograma de atividades

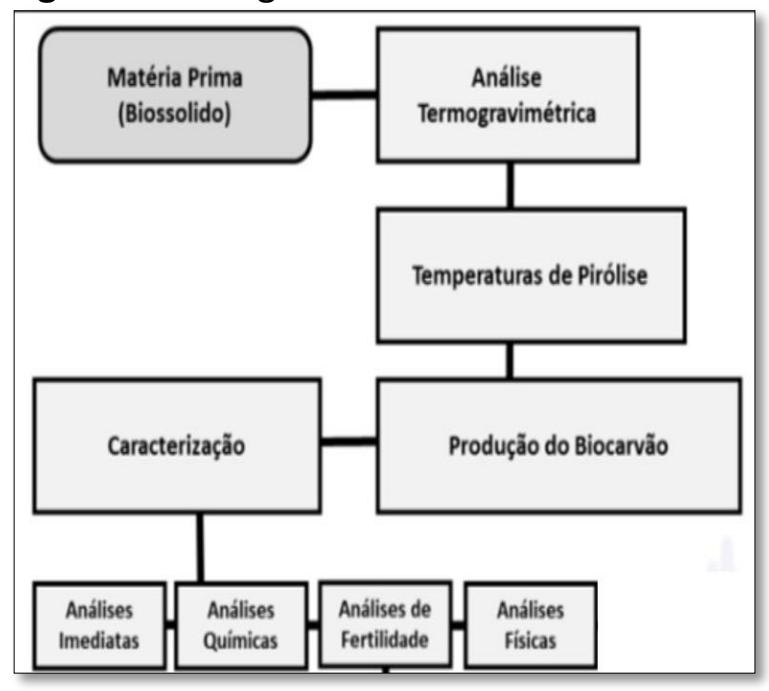

Fonte: Os autores.

\subsection{CARACTERIZAÇÃO DA ÁREA DE ESTUDO}

Segundo o Governo de Rancharia (2019), Rancharia é um município brasileiro do estado de São Paulo. Sua população estimada pelo IBGE em 2018 era de 29. 688 habitantes. Sua área territorial corresponde a $1.587,498 \mathrm{~km}^{2}$.

\subsection{AQUISIÇÃO DA MATÉRIA PRIMA}

Para realização deste trabalho utilizou-se o biossólido fornecido pelo SAE (Serviço de Água e Esgoto) de Rancharia - SP Esse material é resultante de um processo que envolve o armazenamento do lodo de esgoto em lagoas de decantação. Posteriormente é realizada a dragagem desse material (lama, lodo e outros sedimentos) para o interior dos bags geotêxteis ou também cognominados de bags de desidratação, pois realizam uma filtragem desse material retirando toda a água do componente e retendo apenas os resíduos sólidos (PIEPER, 2008).

\subsection{ANÁLISE DE TERMOGRAVIMÉTRICA}

Para obter-se ciência das temperaturas viáveis a serem submetidos os materiais, fez-se necessário uma análise de termogravimétrica (Figura 2). A análise então possibilitou a escolha das temperaturas a serem trabalhadas no presente estudo, sendo optado por $200^{\circ} \mathrm{C}$ e $550^{\circ} \mathrm{C}$ em que obteve certa estabilidade na perda de massa do material.

Ressalta-se que entre as temperaturas $0^{\circ} \mathrm{C}$ e $100^{\circ} \mathrm{C}$, houve desidratação do material, visto que esta última refere-se à temperatura de ebulição da água e por isso, esse decréscimo exuberante, tornando inviável a escolha de tal temperatura. Todavia, a partir da temperatura de $200^{\circ} \mathrm{C}$ até $450^{\circ} \mathrm{C}$ aproximadamente, pôde-se constatar excessiva perda de material descartando então, a possibilidade de escolher uma dessas temperaturas. Esse decréscimo de massa pode ter ocorrido em razão de algum composto químico ter se volatilizado ao atingir essas temperaturas.

A partir da temperatura de $500^{\circ} \mathrm{C}$, certificou-se uma estabilidade fixa de sua massa, e assim, optou-se pela temperatura de $550^{\circ} \mathrm{C}$ como sendo a segunda e última para o processo de pirólise. Desse modo, trabalhou-se com 0 processo nas temperaturas de $200^{\circ} \mathrm{C}$ e $550^{\circ} \mathrm{C}$ e ainda, o lodo puro para possível forma de controle e comparação posteriormente.

Figura 2. Análise termogravimétrica

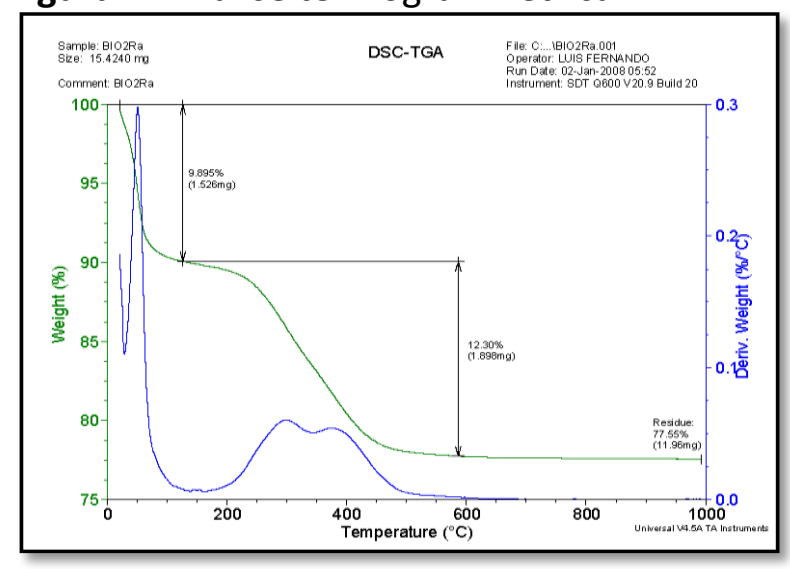

Fonte: Os autores. 


\subsection{DELINEAMENTO EXPERIMENTAL E PREPARAÇÃO DO BIOCARVÃO}

Aplicou-se o delineamento
inteiramente casualizado com seis
repetições. Os tratamentos foram
constituídos pelos biocarvões obtidos pelas
temperaturas de pirólise de $200^{\circ} \mathrm{C}$ (BC 200) e
$550^{\circ} \mathrm{C}$ (BC 550$)$ - totalizando doze amostras -
tendo o lodo de esgoto in natura como
controle.

Produziu-se os biocarvões a partir da amostra seca de lodo de esgoto com o apoio de um reator que foi inserido na mufla com o material, para a pirólise do biocarvão. Para cada batelada de produção do mesmo, cerca de $600 \mathrm{~g}$ do biossólido, foi submetido à temperatura inicial de $100^{\circ} \mathrm{C}$, passando para uma taxa de aquecimento de $10^{\circ} \mathrm{C} \mathrm{min}^{-1} \mathrm{e}$ temperaturas finais de carbonização de 200 e $550^{\circ} \mathrm{C}$, permanecendo 30 minutos na temperatura final. Após o repouso de 24 horas para o resfriamento, o material que estava no interior da mufla foi pesado e identificado para análises posteriores.

\subsection{ANÁLISES IMEDIATAS}

Após a preparação do biocarvão concluída, iniciaram-se as análises imediatas, tais como: Teor de umidade do carvão; Materiais Voláteis; Teor de Cinzas; Teor de carbono fixo; a fim de avaliar o comportamento do biocarvão após passar por elevadas temperaturas, e a título de comparação com outras temperaturas de pirólise.

\subsection{ANÁLISES QUÍMICAS E DE FERTILIDADE}

Estas análises foram realizadas a fim de compreender o comportamento químico da amostra, tanto em seu estado natural, como depois de sofrer as temperaturas de pirólise para identificar a CTC (Capacidade de troca de cátions) e a CTA (Capacidade de troca de ânions), e comparar futuramente se as temperaturas submetidas foram suficientes para adequar a amostra de biocarvão para ser dispersa em solo.

\subsection{ANÁLISES FÍSICAS}

Foram utilizadas com a finalidade de observar $\mathrm{o} \mathrm{pH}$ e condutividade do biocarvão produzido. Realizou-se também a análise de teor de agregados, a fim de avaliar o comportamento do biocarvão em relação a sua granulometria. Nessa fase também foi realizado o MEV (Microscopia eletrônica de varredura) a fim de obter imagens das amostras com lentes de aproximações de 60, 1000 e 5000 vezes. Ademais, realizou-se a EDS (Espectroscopia de energia dispersiva), na qual tem por finalidade especificar um ponto da imagem fornecida pelo MEV e identificar a composição da amostra naquele determinado ponto.

\section{RESULTADOS E DISCUSSÕES \\ 6.1 CARACTERIZAÇÃO ESTRUTURAL}

Esta análise permitiu o conhecimento dos elementos químicos presentes em grande, média e pequena quantidade na matéria prima do presente estudo, feito na amostra de material puro.

Obteve-se os seguintes resultados: $\mathrm{Si}$ (68,83\%); Fe (12,20\%); Al (6,69\%); P (5,17\%); $\mathrm{S}(2,68 \%) ; \mathrm{Ti}(1,85 \%) ; \mathrm{Ca}(1,29 \%) ; \mathrm{K}(0,83 \%) ;$ $\mathrm{Cu}(0,148 \%) ; \mathrm{Mn}(0,078 \%) ; \mathrm{Pb}(0,069 \%) ; \mathrm{Zn}$ (0,069\%); $\mathrm{Cr}(0,049 \%)$.

\subsection{PRODUÇÃO DE BIOCARVÕES}

Ao submeter as amostras do lodo de esgoto à mufla para o processo de pirólise a $200^{\circ} \mathrm{C}$ (BC 200) e a $550^{\circ} \mathrm{C}$ (BC 500), observase que houve uma redução de suas massas, visto que as mesmas, a princípio eram de 600 gramas. O Gráfico 1 apresenta os valores das massas obtidas ao final do processo de pirólise a $200^{\circ} \mathrm{C}$ e a $550^{\circ} \mathrm{C}$. 
Gráfico 1. Massas dos materiais após o processo de pirólise a $200^{\circ} \mathrm{C}$ e $550^{\circ} \mathrm{C}$

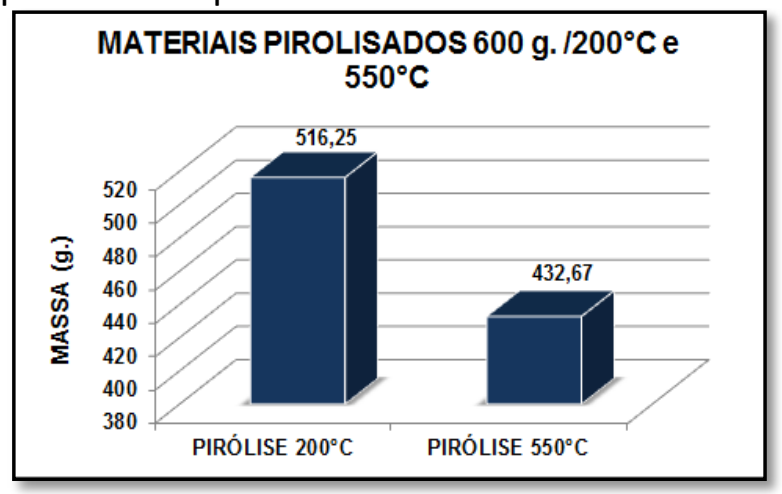

Fonte: Os autores.

\subsection{BALANÇO DE MASSAS}

O Gráfico 2 contém os valores atingidos para os cálculos de balanço de massas. Os resultados são referentes ao Rendimento Gravimétrico - R.G., Rendimento Gravimétrico em Licor Pirolenhoso - R.G.L.P. e Rendimento Gravimétrico em Gases Não Condensáveis (R.G.N.C.). Constata-se que no tratamento BC 550 , em decorrência da perda significativa de massa após o processo de pirólise (Gráfico 1 ), houve um rendimento inferior do material sólido, em comparação com o tratamento BC 200. Por outro lado, devido ao aumento da temperatura, houve maior rendimento do líquido pirolenhoso também no tratamento BC 550, visto que o processo de condensação era mais intenso nessa temperatura e o mesmo ocorreu com os gases que não condensaram.

Gráfico 2. Proporção relativa do balanço de massas dos tratamentos

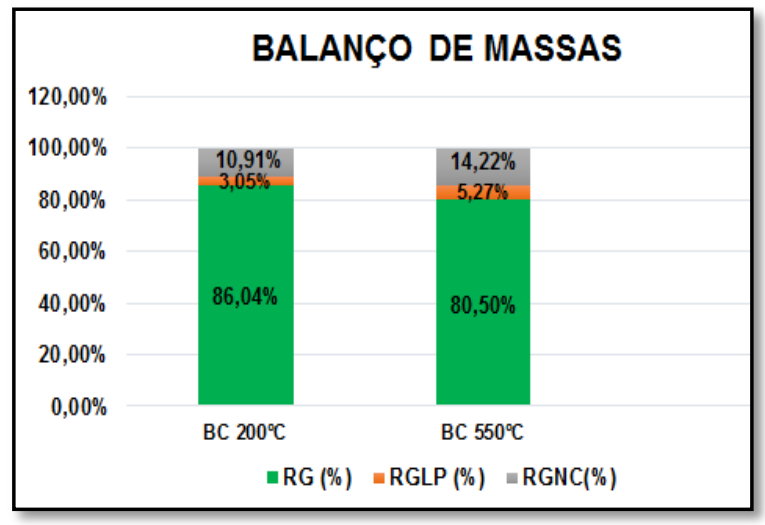

Fonte: Os autores.
Acerca das análises imediatas realizadas com os materiais (Lodo puro, BC 200 e BC 550), a maior parte dos resultados obtidos foi coerente com o que se presumiu. Apresenta-se a seguir, o gráfico contendo os resultados atingidos com o procedimento das análises imediatas (Teor de Umidade, Teor de Cinzas, Materiais Voláteis e Teor de Carbono Fixo) do material puro, bem como dos materiais pirolisados (Gráfico 3).

Gráfico 3. Proporção relativa das análises imediatas

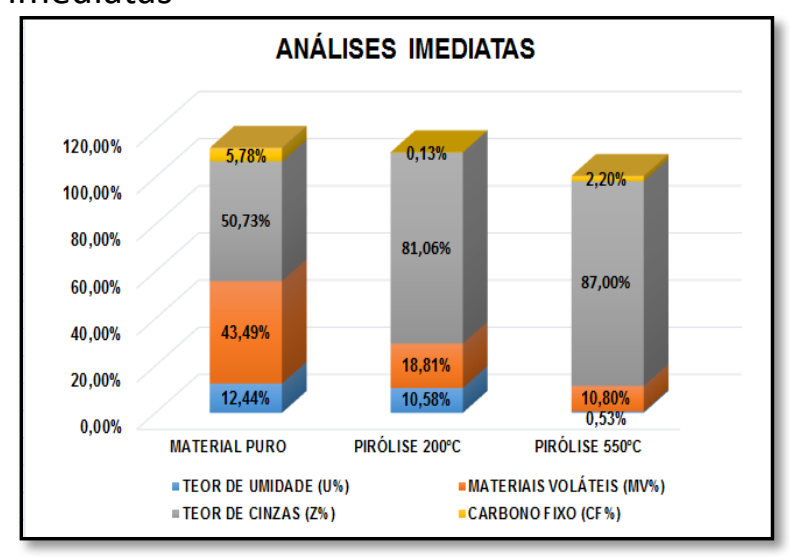

Fonte: Os autores.

\subsection{TEOR DE UMIDADE}

Ao observar os resultados obtidos com a análise de teor de umidade, pode-se concluir que a temperatura de pirólise é inversamente proporcional ao teor de umidade presente no material. Isso ocorre essencialmente em razão da desidratação (perda de água) próxima a temperaturas de $100^{\circ} \mathrm{C}$, fato que justifica o motivo pelo qual o material puro apresentou maior umidade em comparação com os tratamentos BC 200 e sobretudo, BC 550 , em que a discrepância de resultados foi ainda mais elevada.

\subsection{MATERIAIS VOLÁTEIS}

Tratando-se do teor de materiais voláteis, é possível constatar também uma inversão de proporcionalidade referente ao aumento da temperatura de pirólise, ou seja, ao aumentar a temperatura ocorre uma redução de massa dos materiais em decorrência da perda de compostos voláteis presentes que também podem ser gerados 
por transformações químicas no processo de pirólise, acarretando na combustão posterior a uma determinada temperatura entre os tratamentos BC 200 e BC 550 .

\subsection{TEOR DE CINZAS}

Observa-se com os dados apresentados no gráfico que o teor de cinzas apresentou um aumento em razão da elevação de temperatura.

Segundo Conz (2015), o teor de cinzas está associado a quantidade de nutrientes do material, em que essa porção só pode ser obtida após sua completa combustão, da qual todos os elementos orgânicos já terem sido volatilizados.

\subsection{CARBONO FIXO}

De acordo com Conz (2015), o carbono fixo consiste na porção do material que não apresenta compostos voláteis, umidade ou cinzas. Em consequência disso, caracteriza-se por um elemento altamente resistente que permanece no material mesmo após a pirólise. No presente trabalho, os valores obtidos de carbono fixo apresentou um aumento ao elevar-se a temperatura de pirólise de $200^{\circ} \mathrm{C}$ a $550^{\circ} \mathrm{C}$. Isso pode ser explicitado ao fato de que entre a temperatura de $200^{\circ} \mathrm{C}$ e $550^{\circ} \mathrm{C}$, foram sendo formadas novas cadeias aromáticas e compostos químicos mais resistentes que permaneceram no material mesmo com o aumento elevado da temperatura. No entanto, na pesquisa de Artuso (2018), os valores apresentaram uma queda a medida que aumentava-se a temperatura de pirólise.

\subsection{DENSIDADE DE PARTÍCULAS (Dp)}

Ao tratar-se da análise de densidade de partículas dos materiais, pode-se observar que não houve uma alteração expressiva, visto que o volume de álcool etílico consumido não foi muito divergente nas análises. Apresenta-se a seguir, o Gráfico 4 contendo os valores de densidade de partículas obtidos com as análises.
Gráfico 4. Densidade de partículas: material Puro, $200^{\circ} \mathrm{C}$ e $550^{\circ} \mathrm{C}$

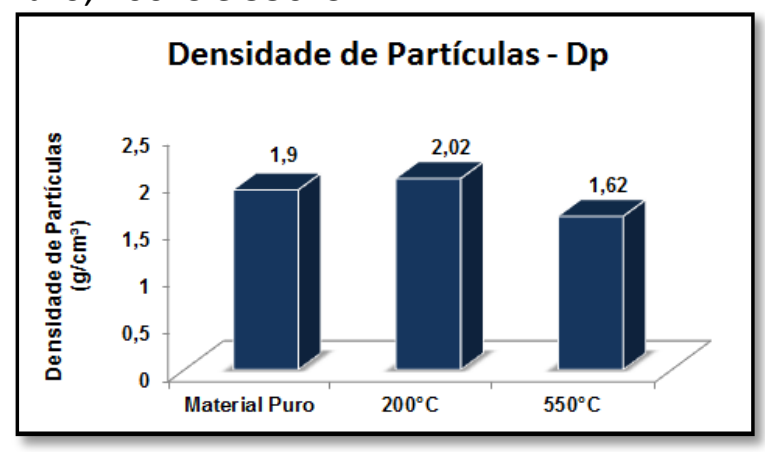

Fonte: Os autores.

Ao analisar o gráfico, nota-se que a densidade de partículas apresentou valor reduzido no tratamento $B C 550$ em relação ao BC 200. Isso sucede pelo aumento da porosidade do material, em decorrência da elevação de temperatura no processo de pirólise lenta. No entanto, a porosidade é desconsiderada em parte na análise de densidade de partículas, uma vez que ela consequentemente é preenchida por álcool etílico, porém, não é possível afirmar que toda a porosidade é efetivamente preenchida e desse modo, o aumento de porosidade pode estar associada a redução de densidade de partículas.

\subsection{POTENCIAL HIDROGENIÔNICO (pH)}

Com o propósito de averiguar mudanças químicas a partir do processo de pirólise das amostras pirolisadas e do material puro, analisou-se o potencial hidrogeniônico das amostras pirolisadas, bem como do material puro para que seja possível a comparação. Os resultados apresentados no Gráfico 5 revelam as alterações ocorridas no $\mathrm{pH}$ das amostras em função da temperatura. 
Gráfico 5. Potencial Hidrogeniônico $(\mathrm{pH})$ : Material Puro, $200^{\circ} \mathrm{C}$ e $550^{\circ} \mathrm{C}$

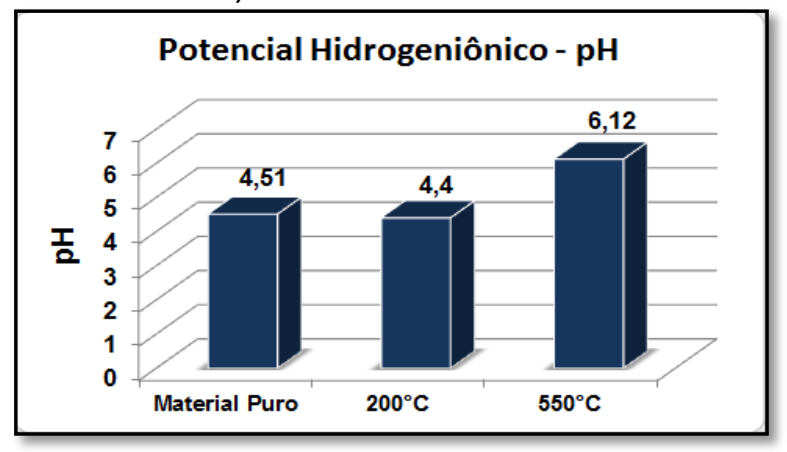

Fonte: Os autores.

De acordo com os resultados obtidos com a análise de Potencial Hidrogeniônico, pode-se afirmar que o biocarvão do tratamento BC 200 não obteve variação significativa em comparação com o pH do material puro, ou seja, apresentou um nível um pouco abaixo da neutralidade. Todavia, o tratamento BC 550 apresentou um resultado mais próximo da neutralidade $\mathrm{e}$ isso comprova o potencial da aplicação do biocarvão produzido nessa temperatura para elevar o pH de solos ácidos. Além do mais, conforme Pereira (2019), a alcalinidade do $\mathrm{pH}$ encontra-se diretamente proporcional ao teor de cinzas, o que pode ser comprovado nos gráficos tratando-se do tratamento $B C$ 550 .

\subsection{CONDUTIVIDADE ELÉTRICA (C.E.)}

Tratando-se da condutividade elétrica dos materiais, realizou-se a análise para averiguar as mudanças em decorrência da elevação de temperatura (Gráfico 6).

Gráfico 6. Condutividade elétrica do material puro e tratamentos.

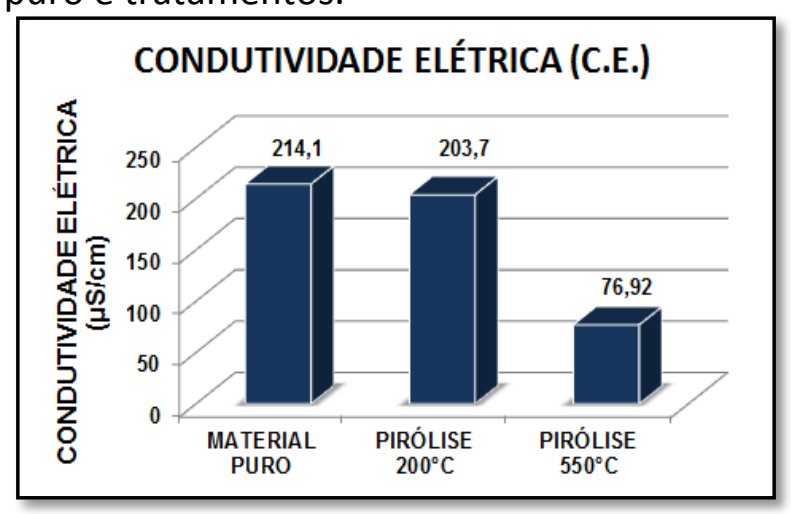

Fonte: Os autores.
É possível perceber que o valor da condutividade apresentou quedas com o aumento das temperaturas. Segundo Artuso (2018), a condutividade elétrica está associada a quantidade de nutrientes existente no material. Ainda segundo o autor em sua análise de C.E. obteve resultados divergentes do presente estudo, visto que o valor da quantidade elétrica em geral foi sendo elevada com o aumento das temperaturas de pirólise, comprovando haver mais nutrientes em seu material. Conz (2015) por sua vez reforçou a ideia de que o material com alta condutividade apresenta mais nutrientes, no entanto, deve-se haver cautela e averiguação dos elementos existentes para evitar uma possível contaminação no solo com a aplicação do biocarvão.

\subsection{TEOR DE AGREGADOS}

A fim de identificar o tamanho das partículas dos materiais pirolisados, bem como o material puro, realizou-se a análise física de teor de agregados. A seguir, o Gráfico 7 contém os valores de cada material submetido a análise por cada peneira.

Gráfico 7. Teor de agregados: material puro, $200^{\circ} \mathrm{C}$ e $550^{\circ} \mathrm{C}$.

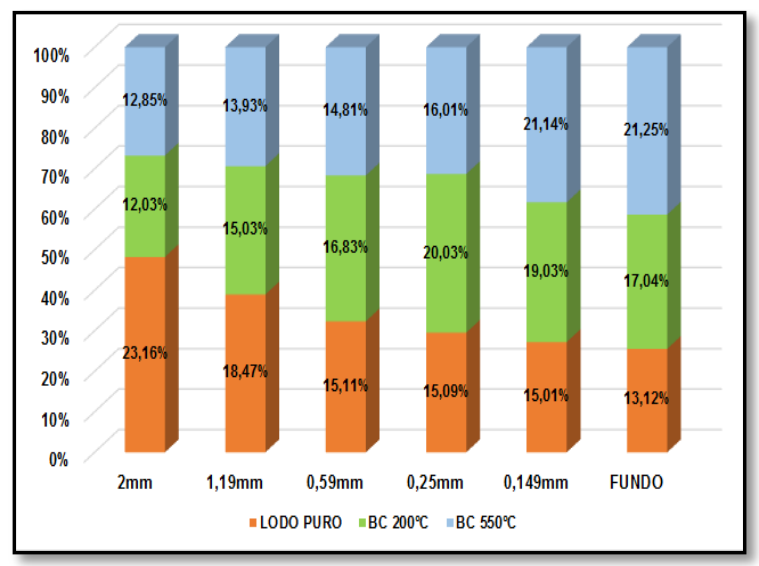

Fonte: Os autores.

Pode-se concluir que o tratamento $B C$ 550 obteve resultados mais satisfatórios, visto que obteve a maior quantidade de partículas menores em comparação com os outros tratamentos, ou seja, partículas com dimensões inferiores a $0,25 \mathrm{~mm}$. O lodo puro 
por sua vez, apresentou valores relativamente baixos para as peneiras de dimensão pequena. Conforme Song et al. (2014), o aumento de microporos colabora na retenção de água e nutrientes no solo e ainda, o aumento de temperatura no processo de pirólise eleva a perda de moléculas de água, consequentemente suscita na formação de microporos e um aumento de até três vezes da área superficial do biocarvão.

\subsection{CAPACIDADE DE TROCA CATIÔNICA}

A análise de CTC (Capacidade de Troca Catiônica) foi realizada com o material puro, bem como com os materiais pirolisados ( $B C$ 200 e BC 550) a fim de obter conhecimento acerca das variações de CTC nas amostras em função das temperaturas e associar isso aos possíveis benefícios ao solo. A seguir, o Quadro 1 apresenta os valores da concentração de CTC nas amostras com seus respectivos volumes consumidos de $\mathrm{NaOH}$ padronizado.

Quadro 01. Capacidade de Troca Catiônica material puro e tratamentos $200^{\circ} \mathrm{C}$ e $550^{\circ} \mathrm{C}$

\begin{tabular}{|c|c|c|}
\hline & $\begin{array}{c}\text { Volume } \\
\text { NaOH } \\
\text { padronizado } \\
(\mathbf{0 , 0 9 9} \mathbf{M}) \\
(\mathbf{m L})\end{array}$ & $\begin{array}{c}\text { Concentração } \\
\text { de CTC } \\
\text { (mmol/Kg) }\end{array}$ \\
\hline $\begin{array}{c}\text { Material } \\
\text { puro }\end{array}$ & 7,9 & 124 \\
\hline $\begin{array}{c}\text { Pirólise } \\
\mathbf{2 0 0} \mathbf{C}\end{array}$ & 2,32 & 14,25 \\
\hline $\begin{array}{c}\text { Pirólise } \\
\mathbf{5 5 0}^{\circ} \mathrm{C}\end{array}$ & 7,7 & 120,76 \\
\hline
\end{tabular}

Fonte: Os autores.

Como pode ser visualizado no quadro acima, o valor da CTC apresentou uma queda significativa do material puro para o tratamento $B C 200$, porém, não apresentou uma variação expressiva, porém ainda assim, o material puro obteve um valor de CTC superior.

Todavia, a CTC do biocarvão mesmo apresentando redução possibilita a contribuição da CTC do solo por mais tempo em razão da sua persistência no solo, divergente da matéria prima que apresenta fácil degradação, conforme Petter e Madari (2012) apud Conz (2015). Ressalta-se que CTC corresponde à soma das cargas negativas que possibilitam a retenção dos cátions no meio.

\subsection{MICROSCOPIA ELETRÔNICA DE VARREDURA (M.E.V.)}

A análise de M.E.V. fez-se possível obter as imagens em diferentes níveis de aproximações (60x, 1000x e 5000x). Sendo assim, as autoras conseguiram visualizar a superfície do material, bem como sua estrutura e granulometria e perceber a diferença ao longo do aumento da temperatura. A Figura 3 apresenta o resultado obtido com uma das análises, em uma lente de aumento de 5000X no BC 200. A Figura 4 apresenta a amostra com a mesma aproximação da anterior, mas agora na temperatura de BC 550 .

Figura 3. M.E.V. BC 200 (5000x).

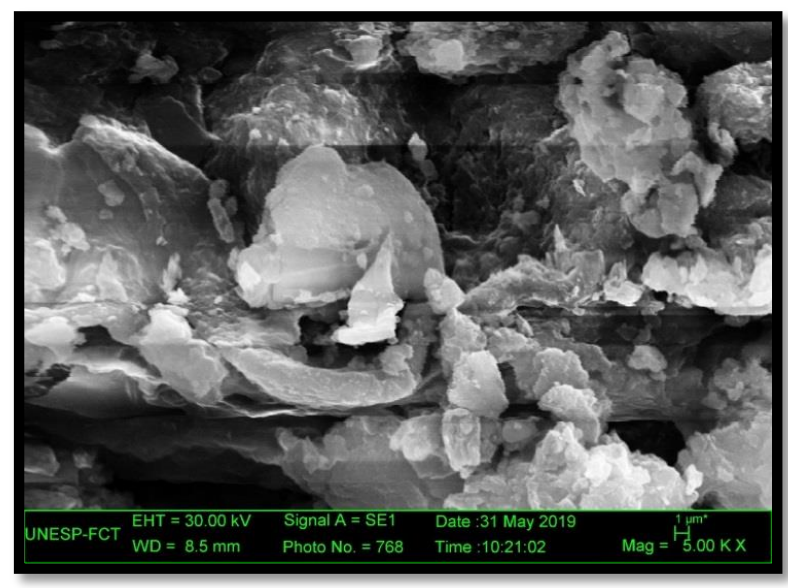

Fonte: Os autores 
Figura 4. M.E.V. BC 550 (5000x).

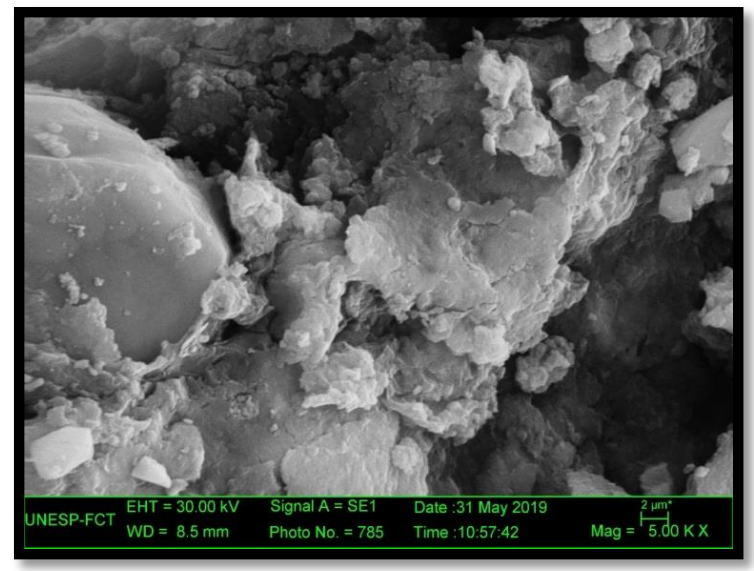

Fonte: Os autores.

A partir das figuras acima, constatouse que a granulometria do material foi reduzindo conforme o aumento de temperatura e as aproximações das imagens pelo aparelho facilitaram a visualização. Ademais, observou-se que a quantidade de grãos menores foi aumentando no tratamento BC 550 .

\subsection{ESPECTROSCOPIA DE ENERGIA DISPERSIVA - E.D.S.}

Ao visualizar e analisar as imagens obtidas pelo aparelho de M.E.V., notou-se que havia uma diferença na superfície e estrutura do mesmo material no BC 550, em que a diferença foi perceptível sobretudo na aproximação de 5000x.
Figura 5. M.E.V. BC 550 (5000x).

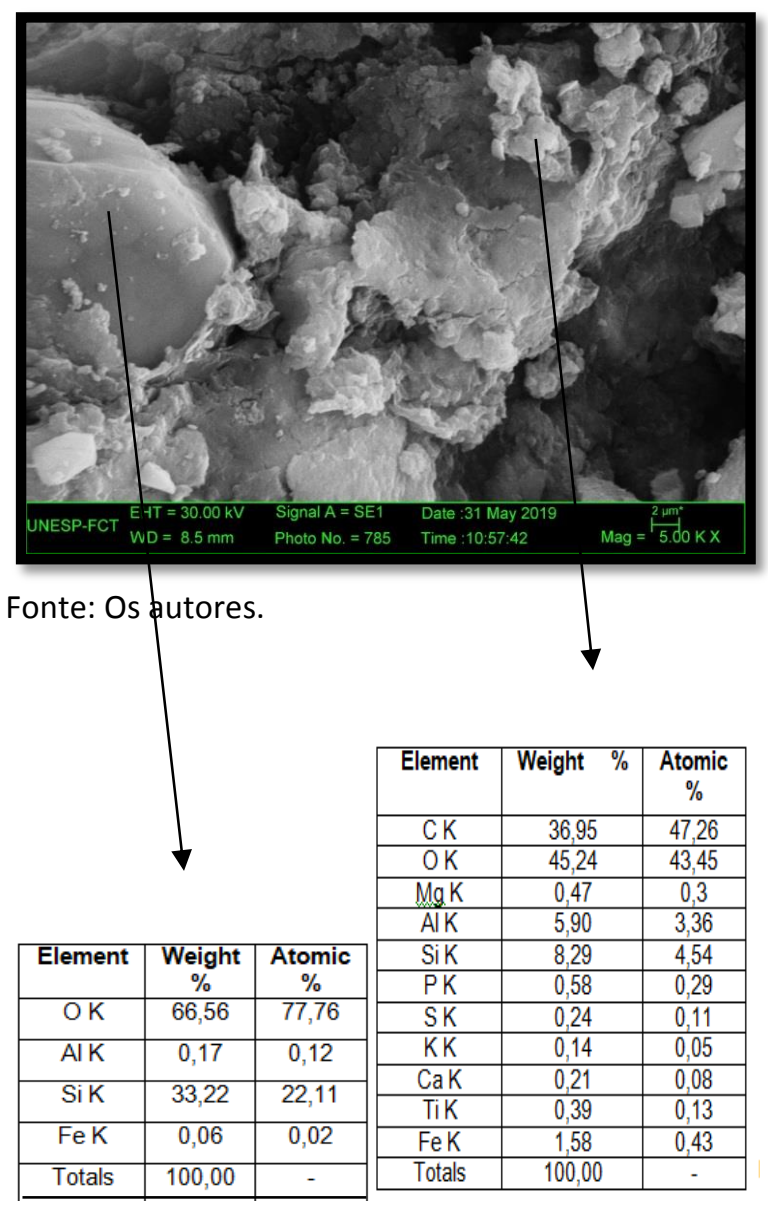

Fonte: Os autores.

Com o propósito de averiguar a composição específica desses materiais na mesma imagem, fez-se necessária a análise de E.D.S. Como representado acima na figura 05, que ainda mostra quais as diferenças percebidas na imagem fornecida pelo aparelho, bem como as composições apresentadas pela análise de E.D.S.

\section{CONSIDERAÇÕES FINAIS}

É de suma importância compreender que na atualidade 0 crescimento populacional influencia diretamente na produção exacerbada de rejeitos e torna-se primordial alcançar maneiras de retorná-las ao meio ambiente com ausência de malefícios, impedindo desta forma que este material fique sem destinação viável. Portanto, a seleção do biocarvão proveniente de lodo de esgoto, por sua significativa carga de matéria orgânica, mostrou-se, de forma geral, benéfica em relação aos resultados obtidos uma vez que, a mesma ao longo do 
processo de pirólise e elevação a altas temperaturas começam a volatilizar os elementos indesejados, e sofre alterações químicas e físicas positivas, tornando-se uma alternativa sustentável para gerenciar o uso de lodo de esgoto posteriormente.

O biocarvão que apresentou melhor rendimento dentro das análises foi na temperatura de pirólise de $550^{\circ} \mathrm{C}$, pois o mesmo obteve perdas significativas de umidade e volatilização de elementos, apresentou mudanças químicas e físicas, e foi possivel observar de forma positiva a melhoria na granulometria final, fator primordial que determina o aprimoramento na retenção de nutrientes.

Todavia, torna-se necessário o investimento em pesquisas complementares, tendo ciência de que cada lodo possui sua composição, e necessita de análises para compreender sua caracterização. Mas, pesquisas similares também apresentam resultados positivos frente a essa biomassa, o que demonstra uma possível utilização sustentável para esse rejeito que antes era visualizado como problema.

\section{AGRADECIMENTOS}

Nosso eterno agradecimento aos colaboradores para que esse projeto fosse concluído com êxito e resultados positivos. Ademais, à Unoeste por todo subsídio fornecido para a realização do trabalho.

\section{REFERÊNCIAS}

AREIAS, I. O. R. et al. Incorporação de lodo da estação de tratamento de esgoto (ETE) em cerâmica vermelha. Cerâmica, São Paulo, v. 63, n. 367, p. 343-349, 2017. https://doi.org/10.1590/0366-

$\underline{69132017633672004}$

ARTUSO, L. F. Produção e caracterização de biocarvão de lodo de esgoto. 2018. Trabalho de Conclusão de Curso (Graduação) Universidade do Oeste Paulista, Presidente Prudente, 2018.
BETTIOL, W.; CAMARGO, O. A. A disposição do lodo de esgoto em solo agrícola. In: BETTIOL, W.; CAMARGO, O. A. de. (Ed.). Lodo de esgoto: impactos ambientais na agricultura. Jaguariúna: Embrapa Meio Ambiente, 2006. p.25-36

BITTENCOURT, S.; AISSE, M. M.; SERRAT, B. $M$. Gestão do uso agrícola do lodo de esgoto: estudo de caso do estado do Paraná, Brasil. Eng. Sanit. Ambient., Rio de Janeiro, v. 22, n. 6, p. 1129-1139, 2017. https://doi.org/10.1590/s141341522017156260

CONZ, R. Caracterização de matérias primas e biochars para aplicação na agricultura. 2015. Dissertação (Mestrado) - Escola Superior de Agricultura "Luiz de Queiroz". Piracicaba, 2015.

PAREDES FILHO, M., V. Compostagem de lodo de esgoto para uso agrícola. Revista AgroAmbiental, v. 3, n. 3, p. 73-80, 2011. doi:http://dx.doi.org/10.18406/2316$1817 v 3 n 32011364$.

FONSECA, A. F. C.; PRADO FILHO, J. F. Um esquecido marco do saneamento no Brasil: o sistema de águas e esgotos de Ouro Preto (1887-1890). História, Ciências, SaúdeManguinhos, v. 17, p. 51-60, 2010. https://doi.org/10.1590/S0104-

$\underline{59702010000100004}$

MAHADAL, S. et al. Avaliação agronômica de um biossólido na produtividade da couve. Revista Tecno-Lógica, v. 20, n. 2, 2016. https://doi.org/10.17058/tecnolog.v20i2.650 $\underline{0}$

PEDROZA, J. P. et al. Produção e componentes do algodoeiro herbáceo em função da aplicação de biossólidos. Rev. bras. eng. agríc. ambient., Campina Grande , v. 7, n. 3, p. 483-488, 2003. https://doi.org/10.1590/S141543662003000300013 
PEREIRA, J. R. C. Potencial do Biocarvão para a Produção de milho e Melhoria da Qualidade do Solo. 2019. Dissertação (Mestrado) - Pós Graduação - Universidade de Pernambuco, Petrolina, 2019.PIEPER, K. M. C. Avaliação do uso de geossintético para o deságue e geoconcentração de resíduos sólidos de estação de tratamento de água. 2008. Dissertação (Mestrado) - UFRGS, Porto Alegre, 2008.

PIRES, A. M. M. AmbienteBrasil. Lodo de Esgoto. [c2019] Disponível em: http://ambientes.ambientebrasil.com.br/resi duos/artigos/lodo_de_esgoto.html. Acesso em: 1 set. 2018

PREFEITURA DO MUNICÍPIO DE RANCHARIA. Rancharia/Dados Gerais. Rancharia: Prefeitura de Rancharia, 2009. Disponível em: http://rancharia.sp.gov.br.

REDAÇÃO. EcoDebate. Uso de lodo de esgoto na agricultura requer cuidados. 2009. Disponível em: https://www.ecodebate.com.br/2009/10/18/ uso-de-lodo-de-esgoto-na-agriculturarequer-cuidados/. Acesso em: 2 set. 2018.

RIGO, M. M. et al. Destinação e reuso na agricultura do lodo de esgoto derivado do tratamento de águas residuárias domésticas no Brasil. Revista Gaia Scientia, v. 8, n.1, p. 174-186, 2014. SONG, X. D.; XUE, X. Y.; CHEN, D. Z.; HE, P. J.; DAI, X. H. Application of biochar from sewage sludge to plant cultivation: Influence of pyrolysis temperature and biochar-to-soil ratio on yield and heavy metal accumulation. Chemosphere, v. 109, p. 213-220, 2014. https://doi.org/10.1016/i.chemosphere.2014 .01 .070 